\title{
Enhancing University Competitiveness through ICT Infrastructure: the Case of Kaunas University of Technology
}

\author{
Regina MISEVICIENE, Kristina SUTIENE, \\ Danute AMBRAZIENE, Dalius MAKACKAS \\ Kaunas University of Technology, Kaunas, Lithuania \\ \{regina.miseviciene |kristina.sutiene |danute.ambraziene \\ |dalius.makackas\}@ktu.edu
}

\begin{abstract}
The crucial factor influencing the main change while shaping the higher education environment over the last decades has been a rapid development of new learning technologies. This paper focuses on presenting the competitive ICT infrastructure that is defined based on the support of student needs in order to complete the higher school. Even though most institutions of higher education can provide a long list of e-services to support student needs, this does not mean that students actively use all of these services. The experience of Kaunas University of Technology is demonstrated using the proposed model of student needs. The usage of KUT e-services is explored by introducing metrics for its analysis.
\end{abstract}

Key words: education, e-services, student needs, competitive infrastructure.

\section{Introduction}

The main challenge for higher education in the nearest future is the global competitiveness (the Bologna process (Wächter, 2004)), as the present global market requires the higher schools to present their courses in the international level. Thus, traditional universities must adapt educational infrastructures in response with the global requirements (Hanna, 2000). What are the essential factors that can influence changes forming the educational infrastructure? A rapid development of new learning technologies, together with their functionalities, is a key driving force influencing these changes and empowering universities to become more innovative. (Mickus, 2009). It is obvious that the introduction of the new technologies requires the preparation of new education environments and methods adapted for these technologies. The development of Information and Communication Technology (ICT) and the occurrence of novel technologies regularly shape the infrastructure of higher schools. With this in mind, this paper focuses on the of ICT infrastructure. What should be the ICT infrastructure for the higher education institutions to enhance their competitiveness?

Despite the fact that higher schools pay special attention to ICT in the educational process, the study of the literature sources has shown that there is no unique methodology of a coverage of study needs by ICT. Many scientific sources evaluate costs and benefits of the use of ICT (Nicol and Coen, 2003). Some authors (David and 
Abreu, 2014) focus in advocating the importance of the recent developments on ICT in education, particularly in higher education. Other authors discuss the general development trends of ICT in this field (Zhang et al., 2016).

So far, there was a general lack of research that would provide the general assessment criteria of competitive ICT infrastructure that can be used as example for other institutions. Higher schools usually develop their own ICT infrastructures based on experts' advice or delegate this task to private IT companies. Thus, this study aims to contribute to this area by filling this gap. As there are no general assessment criteria of competitive infrastructure, throughout the paper we have defined the term "competitive ICT infrastructure" from the point of view of implementation of student needs in order to complete the higher school.

As the analysed scientific literature have not presented a common student needs model, this paper aims to generalize student needs and to present the student needs support model that can be employed by higher education institutions in the development of educational ICT infrastructure in order to enhance its competitiveness.

The paper aim covers the following research tasks:

1. Based on analysis of scientific literature, generalize student needs and present university-wide student needs model that covers not only academic achievements but also promotes the intellectual and personal skills.

2. Explore competitiveness of e-services in Kaunas University of Technology (KUT) on the basis of the student needs model being presented in this paper.

3. Investigate diversity of overall e-services usage and the intensity of average eservices usage.

Research methods include: 1) analysis of scientific literature that was surveyed to create an initial theoretical base; 2) systematic review of KUT legal institutional documentation and reports; 3) interviews with institutional representatives about education policies and practices; 4) retrieval and summarisation of information gathered during the meetings with KUT student organization representatives.

This article begins by presenting generalized model of student needs. Then, article goes on by laying the components of hybrid ICT infrastructure implemented in KUT and the list of e-services provided in KUT with the analysis how these services accomplish with student's needs. The last part of the article presents the usage of e-services provided by KUT.

\section{Student needs' model}

Students are the main users who study at the university. It is important for the students to have the possibility to participate in the study organization process themselves, to use the modern education facilities and to get the knowledge of good quality.

Literature sources on definition of the term "student needs" have been published with a slight growing tendency but anyway are quite limited. Simpson (Simpson, 2013) distinguished academic (or tutorial) support and non-academic support to accommodate student needs. Most authors emphasized only academic importance. For example, the paper (Aoki and Pogroszewski, 1998) divided student needs into four types: administrative, student, faculty, and resource services. The study (Monsour, 1998) defined the needs, such as admission, necessary financial support, technical support, library services, career advisory, counselling, online communication, training programs, administrative, effectiveness monitoring, communication technology, learners' privacy 
and system security, efficient assessment, course quality services, copyright and ownership procedures for course materials, and etc. Other authors (Potter, 2013), (Mickus, 2009), (Pukelyte, 2010) and (Vipartiene, 2013) defined a broader meaning of the term "student support services", like pre-admission counselling, academic advising, financial aid, learning skills instruction, childcare, and much more.

Figure 1 depicts a generalized model of student needs based on the reviewed research papers (Aoki and Pogroszewski, 1998), (Pukelyte, 2010), (Vipartiene, 2013), and a casestudy of KUT. The model was also improved according to the recommendations and experience of KUT IT specialists, as well as based on the requirements defined by KUT Student Union.

\begin{tabular}{|c|c|c|}
\hline Library & Study administration & Finance support \\
\hline Books ordering. & $\begin{array}{l}\text { Registration, } \\
\text { termination or interruption } \\
\text { of studies. Graduation from } \\
\text { the University }\end{array}$ & $\begin{array}{l}\text { The tuition fee and } \\
\text { compensation. }\end{array}$ \\
\hline E-resources. & $\begin{array}{l}\text { Individual study plans. } \\
\text { Mirror studies. }\end{array}$ & $\begin{array}{l}\begin{array}{l}\text { Financial Aid. Study } \\
\text { loans. }\end{array} \\
\end{array}$ \\
\hline $\begin{array}{l}\text { Scientific publications } \\
\text { database. }\end{array}$ & $\begin{array}{l}\text { Knowledge evaluation. } \\
\text { Rotation. Appeals. } \\
\text { Academic Certificates. }\end{array}$ & $\begin{array}{l}\text { Scholarships. Incentive } \\
\text { scholarships. } \\
\text { support }\end{array}$ \\
\hline Life needs & $\begin{array}{c}\text { Course } \\
\text { Course materials. }\end{array}$ & IT services \\
\hline $\begin{array}{l}\text { Accommodation, } \\
\text { dormitories. }\end{array}$ & $\begin{array}{l}\text { Academic environment. } \\
\text { Lectures. }\end{array}$ & E-mail. \\
\hline Health services. & Technical support. & Printing and copying. \\
\hline $\begin{array}{ll}\text { Psychological } & \text { and } \\
\text { spiritual help. } & \end{array}$ & $\begin{array}{l}\text { Documents, events, } \\
\text { news }\end{array}$ & Software for self-study. \\
\hline Catering services. & $\begin{array}{l}\text { Faculty address, } \\
\text { contacts. }\end{array}$ & Wireless network. \\
\hline Leisure & Faculty data. & $\begin{array}{l}\text { Private network. Social } \\
\text { network. }\end{array}$ \\
\hline Sport activities. & $\begin{array}{l}\text { Documents: procedure } \\
\text { descriptions, } \\
\text { regulations. }\end{array}$ & Web services. \\
\hline Student organizations. & FAQ. & Career planning \\
\hline Art societies. & Events, news. & Practice organization. \\
\hline Trade union. & Quality assessment & \begin{tabular}{lr}
\multicolumn{1}{c}{ Exchange } & programs. \\
Internships. & Support for \\
students' & international \\
activity & \\
\end{tabular} \\
\hline $\begin{array}{l}\text { Academic } \\
\text { support }\end{array}$ & $\begin{array}{l}\text { Academic ethics } \\
\text { questions. }\end{array}$ & Scientific research. \\
\hline $\begin{array}{l}\text { Mentorship program: } \\
\text { career mentor, research } \\
\text { mentor, tutor. }\end{array}$ & $\begin{array}{l}\text { Application } \\
\text { penalties. }\end{array}$ & Non-formal education. \\
\hline $\begin{array}{l}\text { Academic assistance: } \\
\text { academic advisor. }\end{array}$ & Surveys. & Part-time jobs. \\
\hline
\end{tabular}

Fig. 1. Student needs' model

The model summarizes the possible student needs in the main areas like studies, finance, library, leisure, IT services, career-planning, documents, events, news, academic help support, study process quality assessment, and other services. 


\section{Analysis of e-services provided to support student needs}

Kaunas University of Technology is running its own hybrid infrastructure (Figure 2), which uses a mix of local university infrastructure and third-party public cloud service provider, such as Microsoft, with orchestration between two platforms.

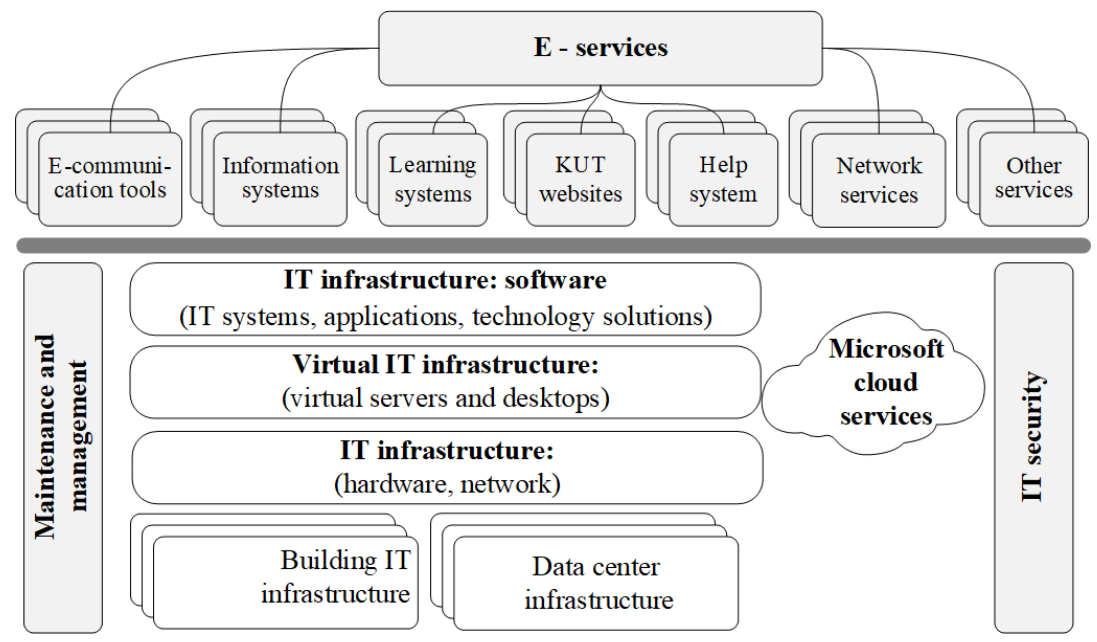

Fig. 2. Hybrid infrastructure of KUT

The top layer (IT infrastructure: software) provides an access to the computing eservices. The applications are implemented and hosted on virtual IT infrastructure. A middle layer contains the system components that manage access to computing resources through the abstraction of software. The components include hypervisors, virtual machines, virtual data centres and other resource abstractions. The lowest layer, as the physical layer, includes all the physical computing resources, such as computers, network, routers, switches, hard disks and other physical components. Maintenance and administration, as well as Security components include security specification, like identity management, authentication and incident management.

This infrastructure allows the university students and staff to access applications via Web, both in computer classes at the University, and for self-working place at home. The originality of the infrastructure is that there are additional functions implemented to manage users who are working with virtual resources. Administrators have opportunity to see how many users are working with virtual resources and to disconnect the users if they are using resources not for work.

All students are provided with University IT user credentials by e-services. KUT eservices that are categorized into seven groups based on their functionality as outlined in Figure 3. Information systems provides capabilities for registering students in courses, making of individual plans and schedules, maintenance of student data and other services. E-communication tools uses Microsoft Office 365 and MS Exchange Online service. Virtual Learning environment provides access of lectures and conferences through student work places and mobile devices and provides capabilities to check students' knowledge on a specific field. University websites branch out into many sections designated to the departments, institutions, centres that, in many cases, have 
their own websites. Help system manages support queries from university community to register incidents. Network services allow securely to connect to the University network. Other services take services like copying; printing and scanning.

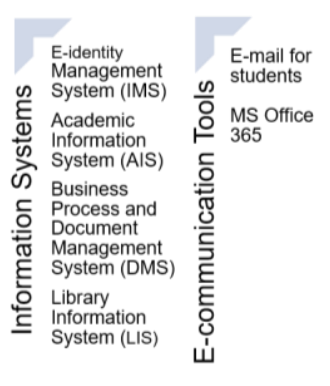

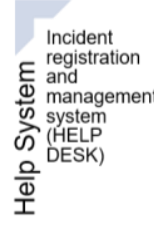
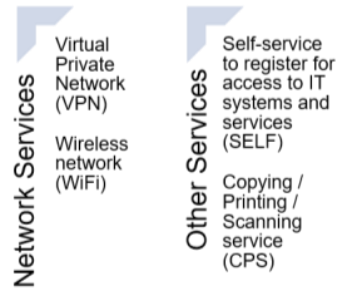

Fig. 3. Classification of e-services provided by KUT

In the article was provided analysis how these services accomplish with students needs specified by proposed student needs model. Figure 4 outlines the results how the student needs specified by the proposed model (Figure 1) are intersected with e-services being provided (Figure 3).

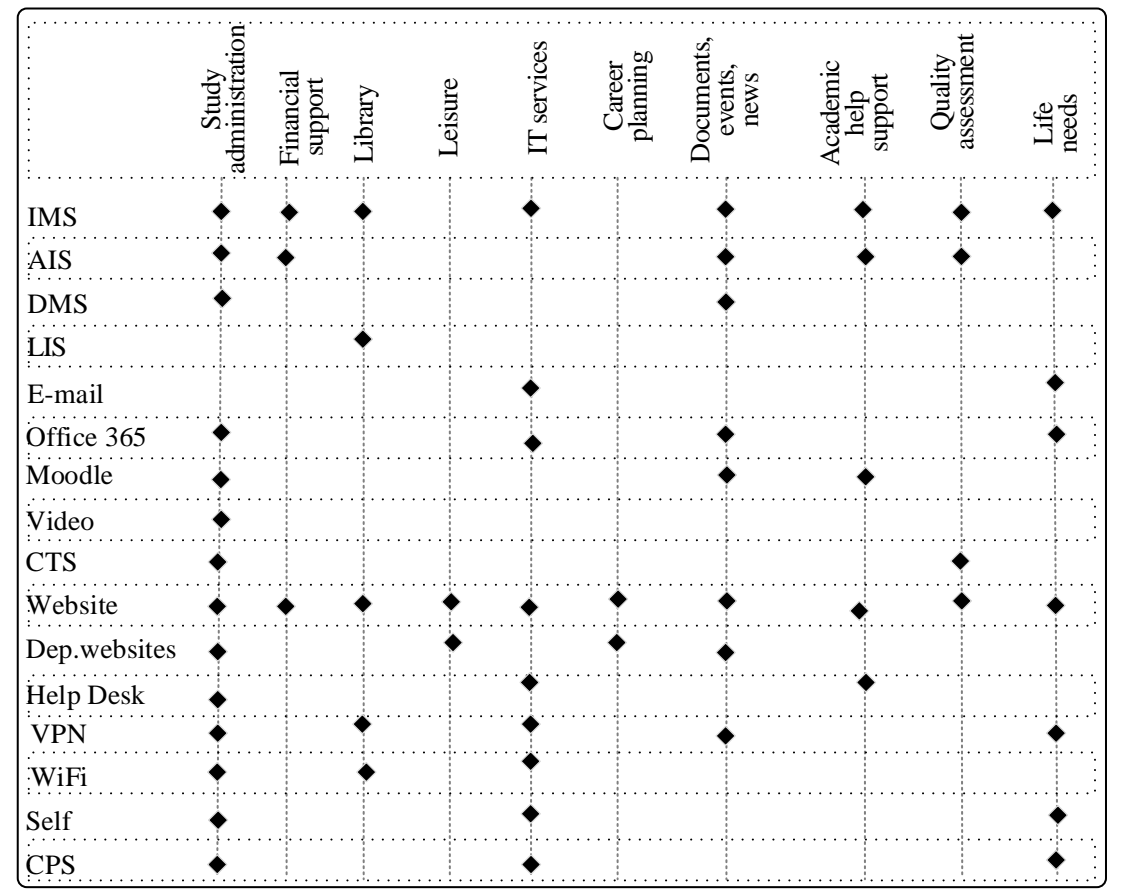

Fig. 4. Relationship between student needs and supported KUT services

Closer inspection of this chart shows that some of e-services are unique and comply with specific student needs, while the others are universal ones and widely applicable. 


\section{Research findings}

The specific questions which drive the research are: Whether students use all of these eservices? Which e-service is the most popular among faculties? How the trend in usage changes over time? In general, the paper concerns with the investigation of diversity of overall e-services usage and the intensity of average e-services usage. In particular, the detailed usage analysis of all e-services presented in Figure 3 is problematic because of limited data access. Thus, among the e-services provided to support student needs in KUT were selected in the following analysis. Empirical data available for this research were collected for AIS, Office365, VLE, and Library e-services over 2016/2017 academic year.

The percentage intensity of average usage for the selected service, $\lambda^{5}$, is estimated by using the measure given by

$$
\lambda^{S}=\frac{1}{D \cdot n} \sum_{i=1}^{n} d_{i}^{S} \cdot 100 \%
$$

where $D$ - the number of days within the academic year, $n$ - the number of students in the university or faculty, $d_{i}^{S}-$ the number of days when the student $i$ accessed the concrete e-service $S$ through IMS. The estimated values for each KUT faculty per academic year are shown in Figure 5.

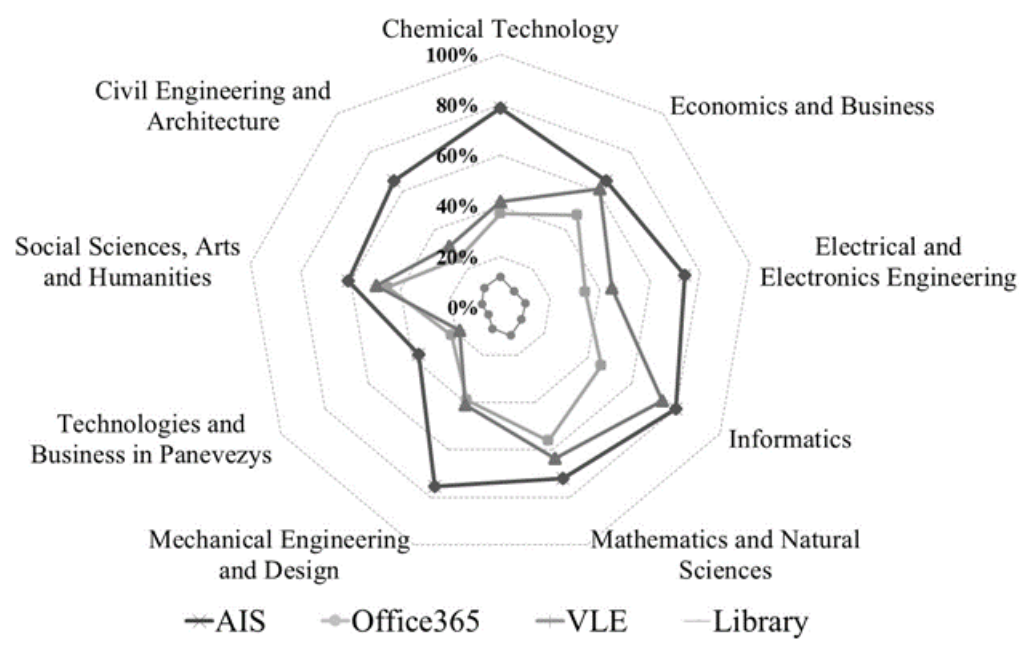

Fig. 5. The percentage intensity of average usage of selected e-services

As can be seen from Figure 5, the percentage intensity of e-services, such as AIS, Office 365, VLE, Library, being used by the students directly corresponds to the needs of the specific faculty where predominantly either engineering or business-social orientation in education is set up. Student needs at engineering faculties are characterized by high values of almost all e-services analysed. The overall mean level of 
percentage intensity of average usage per faculty for each e-service is summarized in Table 1. The table shows that in average AIS e-service, being as the most popular eservice, was used 68 percent of days per academic year. In general, the intensity level was consistent with the need of these services in the education process, but not the Library case, which was accessed only up to 10 percent of days.

Table 1. The overall mean level of percentage intensity of average usage per faculty

\begin{tabular}{|l|c|c|c|c|}
\hline The overall level of & AIS & Office365 & VLE & Library \\
\cline { 2 - 5 } percentage intensity, \% & 67.61 & 39.18 & 47.24 & 9.30 \\
\hline
\end{tabular}

The next step of the analysis concerns the statistical data that were collected to investigate the diversity of overall e-services usage in terms of the number of unique users that login to the e-services being analysed. The estimate $\mu_{\tau}^{5}$ of usage as defined is formalized by

$$
\mu_{T}^{\S}=\frac{1}{T} \sum_{\mathrm{t}=1}^{T} k_{\mathrm{t}}^{\Phi} ;
$$

where, $T$ - the length of a period to be selected of the analysis, $k_{t}^{\text {service }}$ - the number of unique logins to a certain e-service $S$ per unit time $t$. The estimated values of $\mu_{T}^{5}$ for each service setting up either $T$ equal to the time frame over which the usage is being calculated or $T^{n}$ as one month are shown in Figure 6a) and in Figure 6b), respectively.

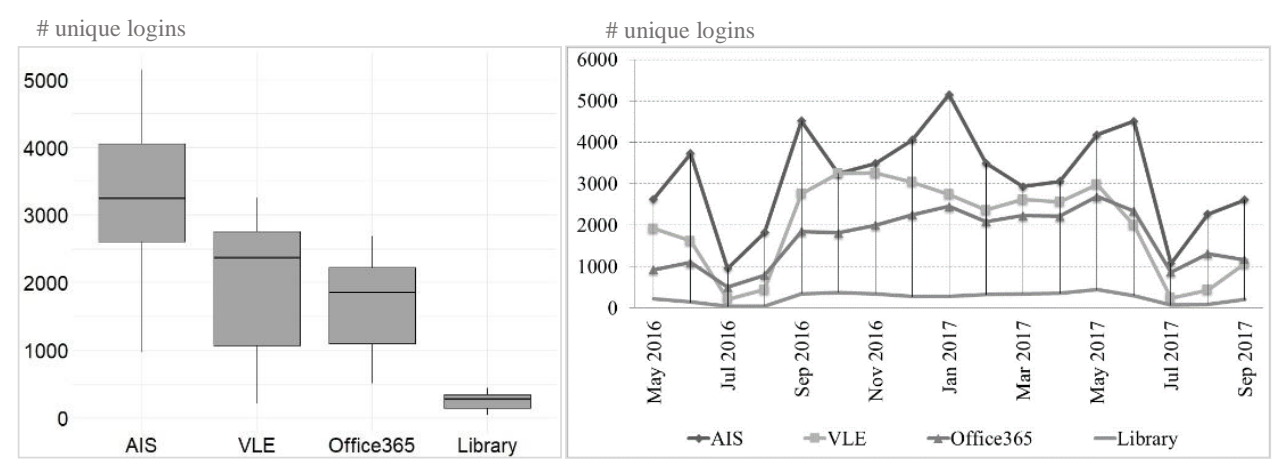

a) Variation among e-services

b) Variation over time

Fig. 6. Usage of e-services during 2016/2017 academic year

Nearly 10 thousand students were studying at KUT during 2016/2017 academic year. It is apparent from Figure 6a) that AIS service, having the highest variation, was observed as the mostly used by students as compared with the other e-services. The number of unique logins for VLE and Office 365 services was more or less similar in comparison. From the Figure 6a), one can see that by far the lowest demand was for Library's e-service. This is rather unexpected outcome that usage of services provided by Library was rather low and kept the same level during whole academic year, as can 
be seen in Figure 6b). The administrative authorities should concern about this evidence obtained during the analysis. Figure $6 b$ ) depicts the dynamics of usage of e-services that can be described as having a certain pattern implied by three critical time moments, such as the beginning of academic year and the end of each semester. The usage of VLE and Office 365 can be distinguished from the others by a sharply rise at the beginning of academic year, then levelling off at approximately its maximum usage before a slight fall at the end of first semester. AIS e-service produced the similar dynamics but contrary to the others had a peak at the end of first semester. The usage of Library e-service remained rather stable with slight fluctuation over the whole year.

\section{Conclusions and discussion}

The research has identified that there is a general lack of scientific publications that would present key criteria for assessing the infrastructure of higher education institution. Therefore, this paper contributes to this field by proposing student needs scheme that includes not only academic development and achievements but also promotes the intellectual and personal skills acquired during studies in the university.

The case study has demonstrated the assessment of KUT experience to the adaption of ICT strategy based on the presented model in order to enhance its competitive advantage. As anticipated, our research has demonstrated that a long list of implemented ICT services can lead to low usage rates of certain e-services. The discrepancy between the provision and the usage is crucial if these services relate to the academic development of students and competitiveness of institution.

The paper creates a paradigm for future studies focusing on the development of ICT infrastructure to ensure its sustainability.

\section{References}

Aoki, K., Pogroszewski, D. (1998). Virtual University Reference Model: A Guide to Delivering Education and Support Services to the Distance Learner. Online journal of distance learning administration, 1(3), http://www.westga.edu/ distance/aoki13.html.

David, F., Abreu, R. (2014). Information technology in education: Recent developments in higher education. Information Systems and Technologies (CISTI), 2014 9th Iberian Conference, pp. 1-6. IEEE DOI: 10.1109/CISTI.2014.6876950.

Hanna, D. E. (2000). Higher Education in an Era of Digital Competition: Choices and Challenges. Madison: Atwood Publishing.

Mickus, A. V. (2009). ICT and online study methods in traditional face-to-face studies (in Lithuanian). Acta Paedagogica Vilnensia, 23(23), 21-28 .

Monsour, F. (1998). Twenty Recommendations for an Administrative Mentoring Program. NASSP Bulletin, vol. 82 no. 594, 96-100. doi:http://dx.doi.org/10.1177/019263659808259414.

Nicol, D., Coen, M. (2003). A model for evaluating the institutional costs and benefits of ICT initiatives in teaching and learning in higher education. ALT-J, 11(2), 46-60 doi: $10.1080 / 0968776030110205$.

Potter, J. (2013). Beyond access: Student perspectives on support service needs in distance learning. Canadian Journal of University Continuing Education, 24(1), doi:http://dx.doi.org/10.21225/D5R88Q.

Pukelyte, R. (2010). Quality Assesment of University Studies as a Service: Dimentions and Criteria. The Quality of Higher Education, 155-175. Downloaded from https://ejournals.vdu.lt/index.php/QHE/article/view/977/901 
Simpson, O. (2013). Supporting students in online open and distance learning (3rd Ed.). Routledge: Taylor \& Francis Group.

Vipartiene, K. V. (2013). Survey of user-friendliness of websites of Lithuanian colleges (in Lithuanian). Informacijos mokslai, 135-149. Downloaded from http://www.journals.vu.lt/informacijos-mokslai/article/view/2060/1288

Wächter, B. (2004). The Bologna Process: developments and prospects. European Journal of Education, 39 (3), 265-273. http://dx.doi.org/10.1111/j.1465-3435.2004.00182.x.

Zhang, J., Yang, J., Chang, M., Chang, T. (2016). Towards a Critical Understanding to the Best Practices of ICT in K-12 Education in Global Context. ICT in education in global context, 1-17. http://dx.doi.org/10.1007/978-981-10-0373-8_1.

Received June 21, 2018, accepted June 25, 2018 